\title{
Gold catalysts supported on ceria doped by rare earth metals for water gas shift reaction: Influence of the preparation method
}

\author{
D. Andreeva ${ }^{\mathrm{a}, *}$, I. Ivanov $^{\mathrm{a}}$, L. Ilieva ${ }^{\mathrm{a}}$, M.V. Abrashev ${ }^{\mathrm{b}}$, R. Zanella ${ }^{\mathrm{c}}$, J.W. Sobczak ${ }^{\mathrm{d}}$, W. Lisowski ${ }^{\mathrm{d}}$, \\ M. Kantcheva ${ }^{\text {e }}$, G. Avdeev ${ }^{\text {f }}$ K. Petrov ${ }^{f}$ \\ a Institute of Catalysis, Bulgarian Academy of Sciences, “Acad. G. Bonchev" str., bl.11, 1113 Sofia, Bulgaria \\ ${ }^{\mathrm{b}}$ Faculty of Physics, University of Sofia, 1164 Sofia, Bulgaria

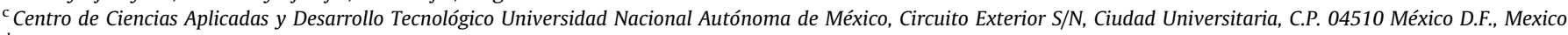 \\ ${ }^{\mathrm{d}}$ Institute of Phys. Chem., PAS, Kasprzaka 44/52, 01-224 Warsaw, Poland \\ e Department of Chemistry, Bilkent University, 06800 Bilkent, Ankara, Turkey \\ ${ }^{\mathrm{f}}$ Inst. of General \& Inorg. Chem., BAS, Acad. G.Bonchev Str., bl.11, 1113 Sofia, Bulgaria
}

\section{A R T I C L E I N F O}

\section{Article history:}

Received 10 November 2008

Received in revised form 6 January 2009

Accepted 7 January 2009

Available online 24 January 2009

\section{Keywords:}

Gold catalysts

WGS

Ceria doped by Yb, Sm, Gd, Y, La

XRD

HRTEM

Raman

XPS

TPR

\begin{abstract}
A B S T R A C T
Gold catalysts based on ceria, doped by various RE metals (La, Sm, Gd, Yb, Y) were studied. The influence of the preparation methods on structure, properties and catalytic activity in the WGS reaction was investigated. The catalysts' supports were prepared using two different methods: co-precipitation (CP) and mechanochemical activation (MA). The catalysts were tested in a wide temperature interval without and after reactivation. All samples were characterized using a combination of X-ray diffraction (XRD), high resolution transmission electron microscopy (HRTEM), Raman spectroscopy (RS) and X-ray photoelectron spectroscopy (XPS) and TPR. It was found that the catalytic activity of MA catalysts is higher than CP ones. The gold catalysts based on ceria doped by Yb and Sm exhibited the highest activity. After reactivation in air the MA samples almost kept the WGS activity same, while the CP catalysts increased it. The catalysts of a single- and double-phase structure are formed as a result of CP and MA preparation, respectively. There are no big differences in the gold particles size (2-3 nm) depending on dopants and on the preparation techniques. The RS spectra analysis indicates that most probably the oxygen vacancies are adjacent to $\mathrm{Me}^{3+}$ dopant and the ceria structure seems to be better ordered than in the case of alumina as a dopant. There is no distinct correlation between reducibility and WGS activity. The XPS analysis disclose positively charged gold particles in addition to metallic gold within a surface region of fresh samples and only metallic gold on the samples after catalytic processing. There is no simple correlation between the concentration of $\mathrm{Ce}^{3+}$ in the samples and their WGS activity.
\end{abstract}

(c) 2009 Elsevier B.V. All rights reserved.

\section{Introduction}

Gold catalysts based on ceria are very promising for various applications, among them very important one is the production of pure hydrogen via water gas shift (WGS) reaction [1-4]. Metal/ ceria catalysts are several orders of magnitude more active than metal/alumina or other oxide supports for a number of redox reactions [5-7]. Metal-modified ceria has a higher oxygen capacity and reducibility than pure ceria $[1-3,8]$. The addition of different metal dopants with valences lower than $(4+)$ to $\mathrm{CeO}_{2}$ leads to the formation of oxygen vacancies in ceria $[9,10]$. In our previous papers [2,3], we have shown that the addition of $\mathrm{Al}^{3+}$ to ceria increases additionally the oxygen capacity, respectively the WGS

\footnotetext{
* Corresponding author.

E-mail address: andreev@ic.bas.bg (D. Andreeva).
}

activity as well as the stability of gold and ceria against agglomeration. The last feature is directly connected with the stability of gold supported catalysts. It was also found that the method of synthesis of the mixed oxide support plays an important role for the reactivity of these catalysts $[2,3]$.

In the last few years one can observe a dynamic growth of the interest to the WGS due to the very effective way for pure hydrogen production in respect to fuel-cell power systems. Besides, WGS is one of the key steps involved in the automobile exhaust neutralization since the produced hydrogen is very effective reducing agent for $\mathrm{NO}_{x}$ removal. Many authors have studied different noble metal supported catalysts in this reaction [11-15]. Recently, Panagiotopoulou and Kondarides [14] have investigated the effect of the support nature on the catalytic performance of noble metal catalysts for the WGS reaction as well as the WGS activity of Me doped $\mathrm{Pt} / \mathrm{CeO}_{2}$ catalysts [15]. They concluded that WGS activity of Pt and Ru catalysts does not depend on the metal loading, dispersion of crystallite size, but 
depends strongly on the nature of metal oxide carrier [14]. They have also studied the influence of the doped $\mathrm{Pt} / \mathrm{CeO}_{2}$ catalysts by different metals (Ca, La, Mg, Zn, Zr, Yb, Y, Gd) and have established that catalytic activity in WGS depends on the nature of the dopant employed [15]. The application of the WGS gold catalysts to fuel-cell power systems requires high catalytic activity and stability in cyclic operation in a wider operating temperature window than the commercial low temperature shift catalysts. Among the important factors responsible, the support plays a decisive role. In this connection, ceria is a very good choice.

The objective of this paper is to synthesize highly active and stable gold catalysts supported on modified by rare earth metals ( $Y$, $\mathrm{La}, \mathrm{Sm}, \mathrm{Gd}, \mathrm{Yb}$ ) ceria. The mixed oxide supports are prepared by coprecipitation (CP) and by mechanochemical activation (MA) techniques. Depending on the preparation method a comparison between WGS activity and properties of the studied catalysts was considered. The influence of the nature of the dopants on the structure and reactivity of gold catalysts will be discussed as well.

\section{Experimental}

\subsection{Samples preparation}

The mixed $\mathrm{CeO}_{2}-\mathrm{Me}_{2} \mathrm{O}_{3}(\mathrm{Me}=\mathrm{Y}, \mathrm{La}, \mathrm{Sm}, \mathrm{Gd}, \mathrm{Yb})$ supports were prepared by two different techniques. By the 1 st route, a coprecipitation method was applied. A mixed solution of $\mathrm{Ce}(\mathrm{N}-$ $\left.\mathrm{O}_{3}\right)_{3} \cdot 6 \mathrm{H}_{2} \mathrm{O}$ and the corresponding metal nitrates in desired ratio (the amount of $\mathrm{Me}_{2} \mathrm{O}_{3}$ was $10 \mathrm{wt}$.\%) was co-precipitated with a solution of $\mathrm{K}_{2} \mathrm{CO}_{3}$ at constant $\mathrm{pH}=9.0$ and temperature $60{ }^{\circ} \mathrm{C}$. The resulting precursors were aged at the same temperature for $1 \mathrm{~h}$, then filtered and carefully washed until removal of $\mathrm{NO}_{3}{ }^{-}$ions. The washed precipitates were dried in vacuum at $80{ }^{\circ} \mathrm{C}$ and calcined under air at $400{ }^{\circ} \mathrm{C}$ for $2 \mathrm{~h}$. The samples are denoted as follows: CeLaCP, CeSmCP, CeGdCP and CeYCP. By the 2 nd route a mechanochemical activation (MA) was used. The mixed oxide support was prepared by mechanically mixing corresponding metal oxide and freshly prepared vacuum dried cerium hydroxide. Cerium hydroxide was synthesized from the aqueous solutions of $\mathrm{Ce}\left(\mathrm{NO}_{3}\right)_{3} \cdot 6 \mathrm{H}_{2} \mathrm{O}$ and $\mathrm{K}_{2} \mathrm{CO}_{3}$ at the conditions described above. A mixture of cerium hydroxide and corresponding $\mathrm{Me}_{2} \mathrm{O}_{3}$ was subjected to mechanochemical activation by milling for $30 \mathrm{~min}$ in a mortar and calcination at $400{ }^{\circ} \mathrm{C}$ for $2 \mathrm{~h}$. The content of corresponding $\mathrm{Me}_{2} \mathrm{O}_{3}$ was $10 \mathrm{wt}$.\%. Prior to final deposition of $\mathrm{Au}^{3+}$ complexes the mixed oxide support was activated in a UV disintegrator under vigorous stirring. The samples are denoted as follows: CeLaMA, CeSmMA, CeGdMA and CeYbMA.

Gold was introduced by deposition-precipitation method, the theoretical loading was 2 wt.\%. Gold was deposited as $\mathrm{Au}^{3+}$ complexes on the corresponding mixed metal oxide support, preliminary suspended in water. The precipitation was carried out in a "Contalab" system (Switzerland) under full control of all parameters of preparation $(\mathrm{pH}$, temperature, stirring speed, reactant feed flow rates, etc.). The details are given in Ref. [1]. After filtering and careful washing, the precursors were dried under vacuum and calcined in air at $400{ }^{\circ} \mathrm{C}$ for $2 \mathrm{~h}$. The samples were denoted as prepared by co-precipitation - AuCeLaCP, AuCeSmCP, AuCeGdCP and AuCeYCP and by mechanochemical activation - AuCeLaMA, AuCeSmMA, AuCeGdMA and AuCeYbMA.

The undoped $\mathrm{Au} / \mathrm{CeO}_{2}$ sample, used as reference, was also prepared by deposition-precipitation method at the above described conditions [1].

All initial salts used were "analytical grade".

\subsection{Sample characterization}

The BET surface area of the samples was determined on a Micromeritics 'Flow Sorb II-2300' device.
X-ray diffraction (XRD) measurements were performed with an automatic powder diffractometer DRON (Bragg-Brentano arrangement), using $\mathrm{Cu} \mathrm{K} \alpha$ radiation and a scintillation counter. The diffraction patterns were recorded in a step-scan mode with a step of $0.02^{\circ}(2 \theta)$, counting time $1 \mathrm{~s}$, in the angular interval $20-90^{\circ}(2 \theta)$. The powder cell program [16] was used for diffraction data processing. The program gives the possibility of approximation of XRD spectra based on the corresponding theoretical structures. The instrumental broadening was taken into consideration. XRD profiles were approximated by Lorenz functions.

High resolution transmission electron microscopy (HRTEM) observations of the catalysts were performed in a JEM 2010 FasTem analytical microscope equipped with a Z-contrast annular detector. The histograms of the metal particle sizes were established from the measurement of 400 to 500 particles obtained by Z-contrast and thermal diffuse scattering (TDS) observations.

The Raman spectra were recorded using a SPEX 1403 double spectrometer with a photomultiplier, working in the photon counting mode. The 488-nm line of an $\mathrm{Ar}^{+}$ion laser was used for excitation. The laser power on the samples was $60 \mathrm{~mW}$. The samples were prevented from overheating during the measurements by increasing the size of the focused laser spot. The optimal conditions were chosen, checking the intensity, position and the width of the $464 \mathrm{~cm}^{-1}$ Raman line of $\mathrm{CeO}_{2}$. The spectral slit width was $4 \mathrm{~cm}^{-1}$

The TPR measurements were carried out by means of an apparatus described elsewhere [17]. A cooling trap $\left(-40^{\circ} \mathrm{C}\right)$ for removing water formed during reduction was mounted in the gas line prior to the thermal conductivity detector. A hydrogen-argon mixture $\left(10 \% \mathrm{H}_{2}\right)$, dried over a molecular sieve $5 \mathrm{~A}\left(-40^{\circ} \mathrm{C}\right)$, was used to reduce the samples at a flow rate of $24 \mathrm{ml} \mathrm{min}^{-1}$. The temperature was linearly raised at a rate of $15^{\circ} \mathrm{C} \mathrm{min}{ }^{-1}$. The sample mass used was $0.05 \mathrm{~g}$. It was selected by the criterion proposed by Monti and Baiker [18]. In addition, the consecutive TPR experiments were carried out after re-oxidation with purified air at the temperature, immediately after the end of the first TPR peak $\left(220^{\circ} \mathrm{C}\right)$ of the fresh sample. The $\mathrm{H}_{2}-\mathrm{Ar}$ flow was switched over to air flow for $15 \mathrm{~min}$ and the new TPR pattern was recorded after cooling down to room temperature in purified helium. The hydrogen consumption during the reduction processes was calculated using preliminary calibration of the thermal conductivity detector, performed by reducing different amounts of $\mathrm{NiO}$ to $\mathrm{Ni}$ (NiO-"analytical grade" of purity, calcined for $2 \mathrm{~h}$ at $400{ }^{\circ} \mathrm{C}$ to avoid the presence of non-stoichiometric oxygen).

The X-ray photoelectron spectroscopy (XPS) data were recorded on a VG Scientific ESCALAB-210 spectrometer using Al $\mathrm{K} \alpha$ radiation ( $1486.6 \mathrm{eV}$ ) from an $\mathrm{X}$-ray source operating at $15 \mathrm{kV}$ and $20 \mathrm{~mA}$. The spectra were collected with analyser pass energy $20 \mathrm{eV}$, step $0.1 \mathrm{eV}$ and an electron take off angle $90^{\circ}$. The samples were pressed into thin wafers and degassed in a preparation chamber before analysis. The Shirley background subtraction and peak fitting with Gaussian-Lorentzian product peak was performed using a XPS processing program Avantage (Thermo Electron Corporation). The charging effects were corrected by adjusting Ce $3 \mathrm{~d}_{3 / 2}$ peak, usually described as $\mathrm{u}^{\prime \prime \prime}$ peak to a position of $917.00 \mathrm{eV}$ [19-21]. This is a strong, individual peak and its position can be established much more precisely than that of the commonly used $\mathrm{C} 1 \mathrm{~s}$ peak from adventitious carbon.

\subsection{Catalytic activity measurements}

The catalytic activity of the samples expressed as a degree of $\mathrm{CO}$ conversion, was tested in the WGS reaction over a wide temperature range $\left(140-350{ }^{\circ} \mathrm{C}\right)$. The activity was measured in a flow reactor at atmospheric pressure. A gas mixture of initial composition 4.42 vol.\% CO in argon was used. The samples were 
tested in WGS after pretreatment under different conditions: as prepared and after re-oxidation at $200{ }^{\circ} \mathrm{C}$ for $1 \mathrm{~h}$ in air.

The WGS activity was carried out under the following experimental conditions: catalyst bed volume $0.5 \mathrm{~cm}^{3}(0.63-$ $0.80 \mathrm{~mm}$ sieve fraction), space velocity of the dry gas $4000 \mathrm{~h}^{-1}$, partial pressure of water vapour $31.1 \mathrm{kPa}$. The CO content at the reactor outlet was determined on an "Uras 3G" (Hartmann\&Braun AG) gas analyzer.

\section{Results}

\subsection{Catalytic activity}

The temperature dependences of $\mathrm{CO}$ conversion of the as prepared catalysts are represented in Fig. 1. It is visible, that the highest WGS activity is exhibited by AuCeYbMA sample, followed by AuCeSmMA. In Figs. 1 and 3 the equilibrium curve of the CO conversion is given as well. In Fig. 2 the WGS activities of the fresh gold samples supported on nonpromoted ceria and on doped ceria at $240^{\circ} \mathrm{C}$ are compared. This comparison clearly shows that the MA catalysts exhibit higher activities than the corresponding $\mathrm{CP}$ samples. On the other hand the AuCeSmCP sample manifests relatively high activity, higher than other doped MA catalysts.

After 1 week of catalytic processing followed by reactivation of the samples in air at $200^{\circ} \mathrm{C}$, the catalytic test was repeated and the results are presented in Fig. 3. One can see that the activity of the MA samples remains unchanged, except the most active AuCeYbMA catalyst, which activity decreases significantly. Fig. 4 shows the bar diagram of the $\mathrm{CO}$ conversion data taken at $240{ }^{\circ} \mathrm{C}$ for all studied catalysts after their re-oxidation. Some interesting

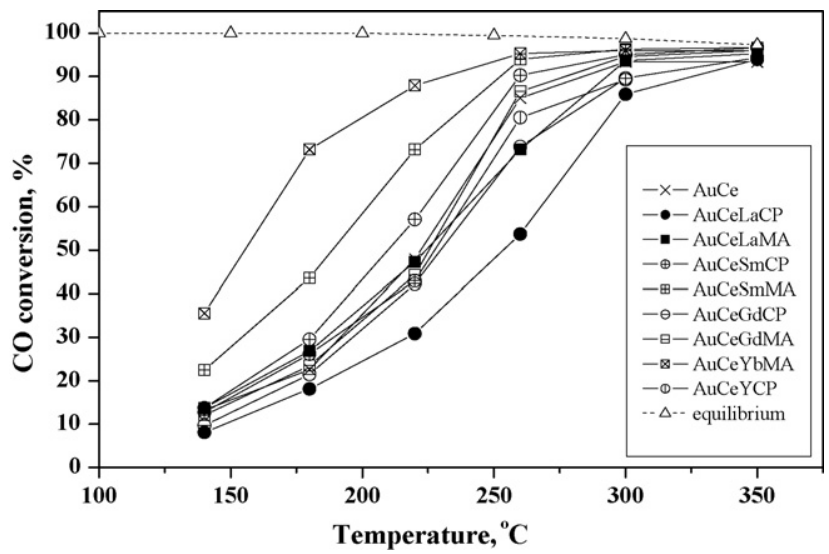

Fig. 1. Temperature dependence of CO conversion over the as prepared catalysts studied.

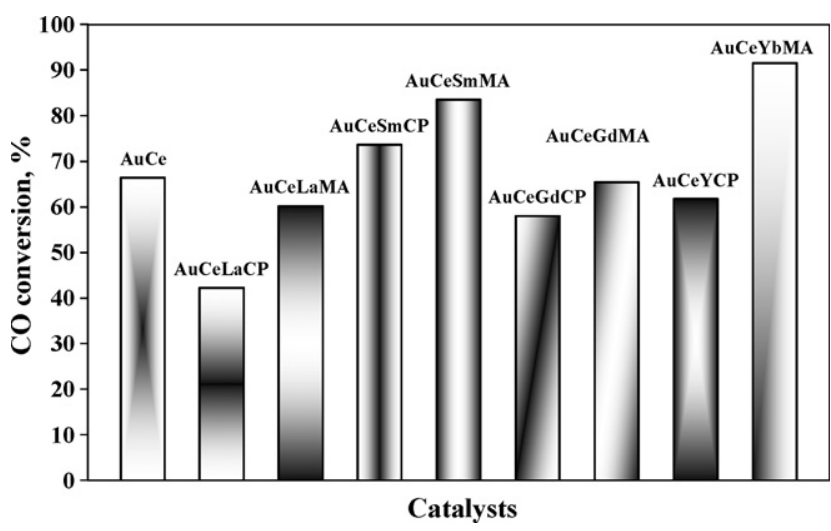

Fig. 2. Catalytic activity data on the studied catalysts at $240{ }^{\circ} \mathrm{C}$.

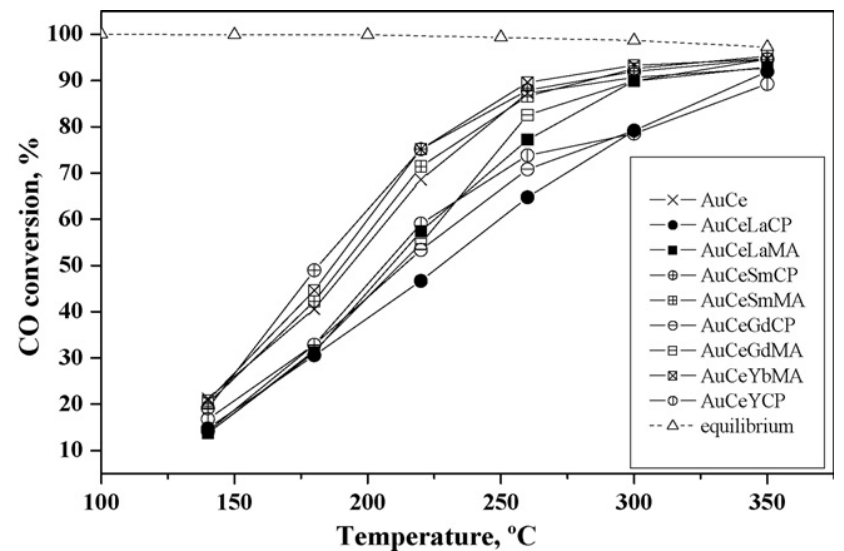

Fig. 3. Temperature dependence of CO conversion of the studied catalysts after reoxidation with air at $200{ }^{\circ} \mathrm{C}$.

points arise after analysis of the WGS activities sequence presented above. Comparing the catalytic activities of the samples before and after re-oxidation, one can see that the MA catalysts kept or slightly decreased their catalytic activity, while for the CP samples the WGS activity even increased, especially in the case of Sm doped catalyst. We have not observed such behaviour for alumina doped gold/ ceria catalysts $[2,3]$. In that case the catalysts supported on MA ceria-alumina exhibited significantly higher activities than the catalysts based on CP support. Another interesting experimental fact, obtained in the present study is that there are no significant differences between the corresponding catalysts CP and MA. Obviously the re-oxidation of ceria surface of $\mathrm{CP}$ samples during catalytic reaction proceeds easier than the corresponding ceriaalumina CP catalysts.

\subsection{Catalysts' characterization}

\subsubsection{XRD analysis}

The X-ray diffraction patterns of the samples of series CP are presented in Fig. 5(a) and (b)-the samples MA. Lattice parameters and mean crystallite size of ceria were calculated from XRD peaks positions and profiles. Data for BET surface area, lattice parameters and mean crystallite size of ceria are presented in Table 1 . In the XRD patterns, lines of gold are not visible due to the low amount of loading as well as the high dispersion. The X-ray diffractogram shows the diffraction lines of $\mathrm{CeO}_{2}$ typical of the cubic crystal structure of fluorite type oxide. All CP samples are single phase, while the all MA samples are double phases. In the last case, the

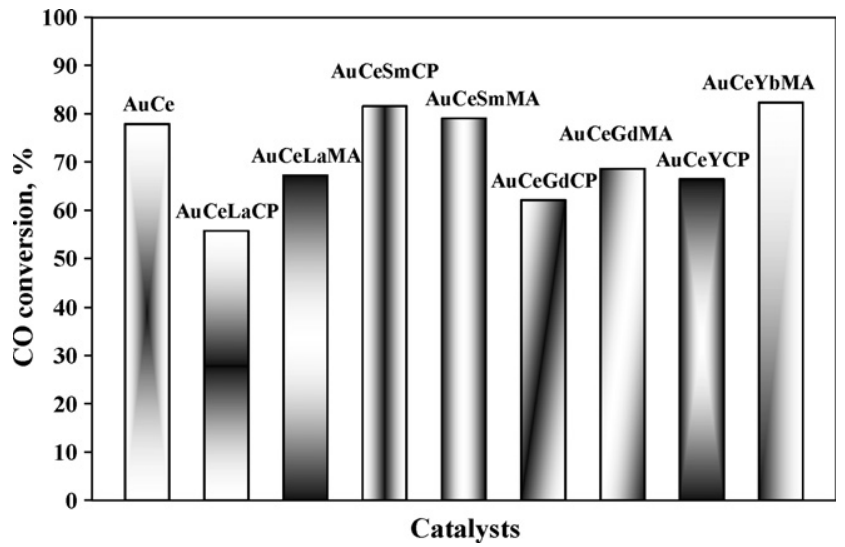

Fig. 4. Catalytic activity data of the catalysts after re-oxidation in air $\left(200^{\circ} \mathrm{C}\right)$ at $240{ }^{\circ} \mathrm{C}$. 

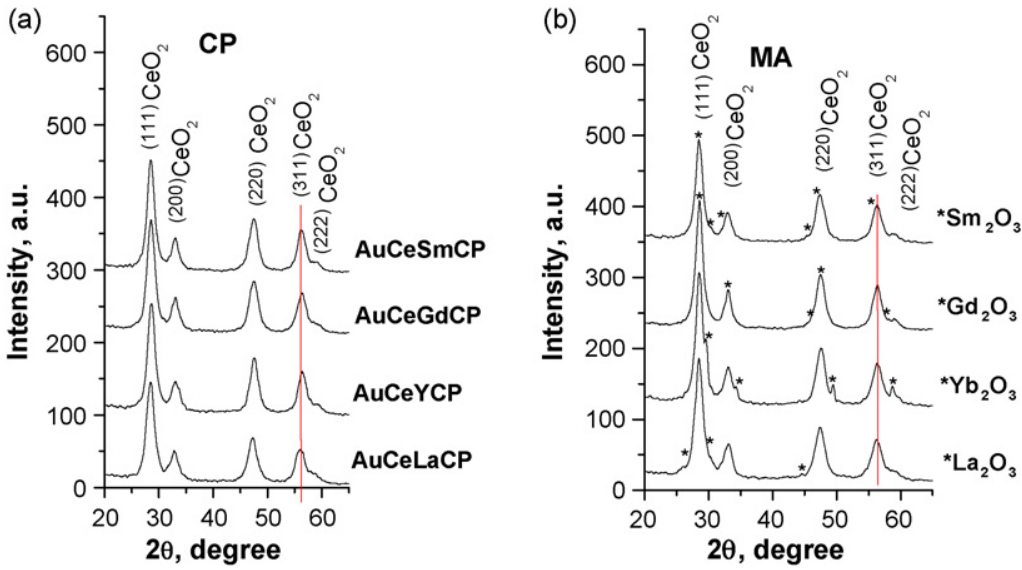

Fig. 5. XRD profiles of the studied catalysts.

phase of the modifier dopant of the corresponding $\mathrm{Me}^{3+}$ (Fig. 5(b)) is observed. The average size of ceria in the CP samples are lower $(6-7 \mathrm{~nm})$ than that for the MA samples $(8.0-9.0 \mathrm{~nm}$, see Table 1$)$. Concerning lattice parameter $\mathbf{a}$, there is no big difference between $\mathrm{CP}$ and MA samples. Only in the case of La doped ceria, the differences between $\mathrm{CP}$ and MA samples are clearly seen, in the case of AuCeLaCP the lattice parameter a is significantly higher than that for AuCeLaMA. The lattice parameters of all studied samples are higher than that of stoichiometric $\mathrm{CeO}_{2}$, but the calculated values are near to the Au supported on pure ceria [3]. The loading of gold to ceria causes a strong modification, resulting in the creation of oxygen vacancies and $\mathrm{Ce}^{3+}[3,22]$. As it is known since ionic radii of $\mathrm{Ce}^{3+}$ is $1.14 \AA$, higher than $\mathrm{Ce}^{4+}(0.97), \mathrm{Ce}^{3+}$ leads to increase of the lattice parameter of ceria. Similarly, $\mathrm{Me}^{3+}$ would replace the available $\mathrm{Ce}^{3+}$ and depending on ionic radii of the metal, the lattice parameter a changes in accordance with these values (see Table 1 ).

\subsubsection{HRTEM data}

HRTEM images of the gold catalysts supported on ceria doped by Sm and La are presented in Fig. 6(a)-(d). The average sizes of the chosen samples are summarized in Table 2. In Fig. 7(a)-(d) are presented the size distribution of gold particles of the studied samples. In all cases between 400 and 500 particles were measured

Table 1

BET surface area, lattice parameters and average size of ceria particles.

\begin{tabular}{lcll}
\hline Samples & $\begin{array}{l}S_{\mathrm{BET}} \\
\left(\mathrm{m}^{2} \mathrm{~g}^{-1}\right)\end{array}$ & $\begin{array}{l}\text { Lattice parameter } \\
\text { of ceria }{ }^{\mathrm{a}, \mathrm{b}} \mathbf{a}(\AA)\end{array}$ & $\begin{array}{l}\text { Average size } \\
\text { of ceria }(\mathrm{nm})\end{array}$ \\
\hline AuCeLaCP & 81 & 5.451 & 6.3 \\
AuCeSmCP & 84 & 5.421 & 7.1 \\
AuCeGdCP & 78 & 5.422 & 6.8 \\
AuCeYCP & 103 & 5.416 & 6.9 \\
AuCeLaMA & 72 & 5.427 & 8.0 \\
AuCeSmMA & 76 & 5.424 & 8.5 \\
AuCeGdMA & 69 & 5.422 & 8.8 \\
AuCeYbMA & 78 & 5.415 & 8.8 \\
\hline
\end{tabular}

a Lattice parameter of $\mathrm{CeO}_{2}=5.412 \AA$, $\mathrm{Au} / \mathrm{CeO}_{2}=5.422[3]$.

b Ionic radii of the dopant metal $(\AA): \mathrm{La}^{3+}, 1.16 ; \mathrm{Sm}^{3+}, 1.079 ; \mathrm{Gd}^{3+}, 1.053 ; \mathrm{Yb}^{3+}$, $0.985 ; \mathrm{Y}^{3+}, 1.019$.

Table 2

Average size of gold particles.

\begin{tabular}{ll}
\hline Sample & Average particle size $(\mathrm{nm})$ \\
\hline $\mathrm{Au} / \mathrm{CeSmMA}$ & 2.4 \\
$\mathrm{Au} / \mathrm{CeSmCP}$ & 2.6 \\
$\mathrm{Au} / \mathrm{CeLaMA}$ & 2.3 \\
$\mathrm{Au} / \mathrm{CeLaCP}$ & 2.5 \\
\hline
\end{tabular}

to obtain the average particle size and the size distribution. It is visible that in the samples MA a relatively higher number of smaller particles were registered compared to the CP samples. The crystallite size distribution of AuCeSmMA sample appears to have two very close peaks with $37 \%$ of the Au crystallites counted having a size of $1.5 \mathrm{~nm}$ and $33 \%$ having a size of $2.5 \mathrm{~nm}$. For the AuCeSmCP sample, this distribution is $19 \%$ having a size of $1.5 \mathrm{~nm}$, $34 \%$ having a size of $2.5 \mathrm{~nm}$ and $22 \%$ having a size of $3.5 \mathrm{~nm}$. The similar pictures are observed for the sample AuCeLaMA and the corresponding AuCeLaCP sample. For AuCeLaMA, the gold crystallites with $1.5 \mathrm{~nm}$ is $35 \%$ and the crystallites with $2.5 \mathrm{~nm}$ is $45 \%$. For the AuCeLaCP sample, the corresponding values are as follows: $1.5 \mathrm{~nm}$ is $21 \%$ and with $2.5 \mathrm{~nm}$ is $51 \%$. Generally it could be said, that there are no big differences in the gold average particle size depending on dopants as well as on the preparation method.

\subsubsection{Raman spectra analysis}

In Fig. 8 are given the Raman spectra (RS) of the initial supports (a, MA supports and b, CP supports) and the gold containing catalysts ( $c$, MA catalysts and d, CP catalysts). One can see that the loading of gold makes spectra strongly absorbing. The main line of $\mathrm{CeO}_{2}$ dominates in the all Raman spectra. In the case of CeSmMA and CeGdMA, the typical lines for $\mathrm{Sm}_{2} \mathrm{O}_{3}\left(344 \mathrm{~cm}^{-1}\right)$ and $\mathrm{Gd}_{2} \mathrm{O}_{3}$ $\left(361 \mathrm{~cm}^{-1}\right)$ are clearly seen, which is in agreement with the XRD results for the bi-phases samples. The frequency's and width's dependence of the ionic radius of the dopant applied are given in Fig. 9. It is visible that the position of the characteristic line of ceria is shifted to the lower frequency in the presence of dopants. McBride et al. [23] have also reported such systematic shift to lower frequency studying $\mathrm{Ce}_{1-x} \mathrm{RE}_{x} \mathrm{O}_{2-y}(\mathrm{RE}=\mathrm{La}, \mathrm{Pr}, \mathrm{Nd}, \mathrm{Eu}, \mathrm{Gd}$, $\mathrm{Tb})$. We have found no direct relationship between the type of dopants and shift character for samples prepared using MA technique. However, for samples prepared by $\mathrm{CP}$ we found the ionic radius to increase as the frequency's values decrease linearly.

It is known, that the broadening of the main line of ceria depends strongly on ceria dispersion and on the concentration of oxygen vacancies formed on the defective structure of ceria [24,25].

As it was shown in Table 1 the average size of ceria crystallites are quite closed for all investigated samples. So the widening should be rather due to the formation of oxygen vacancies in ceria after loading of modifiers. There is no simple relationship between the width's values for the MA samples and the type of doped lanthanides. For the initial supports of the CP catalysts the width is going via minimum at $\mathrm{Sm}$ and $\mathrm{Gd}$ dopants. In gold containing $\mathrm{CP}$ catalysts this dependence is reversed and it is going via maximum for the $\mathrm{Sm}^{3+}$. At this stage of studies it is difficult to explain this experimental fact, however we suppose that it could be related to 


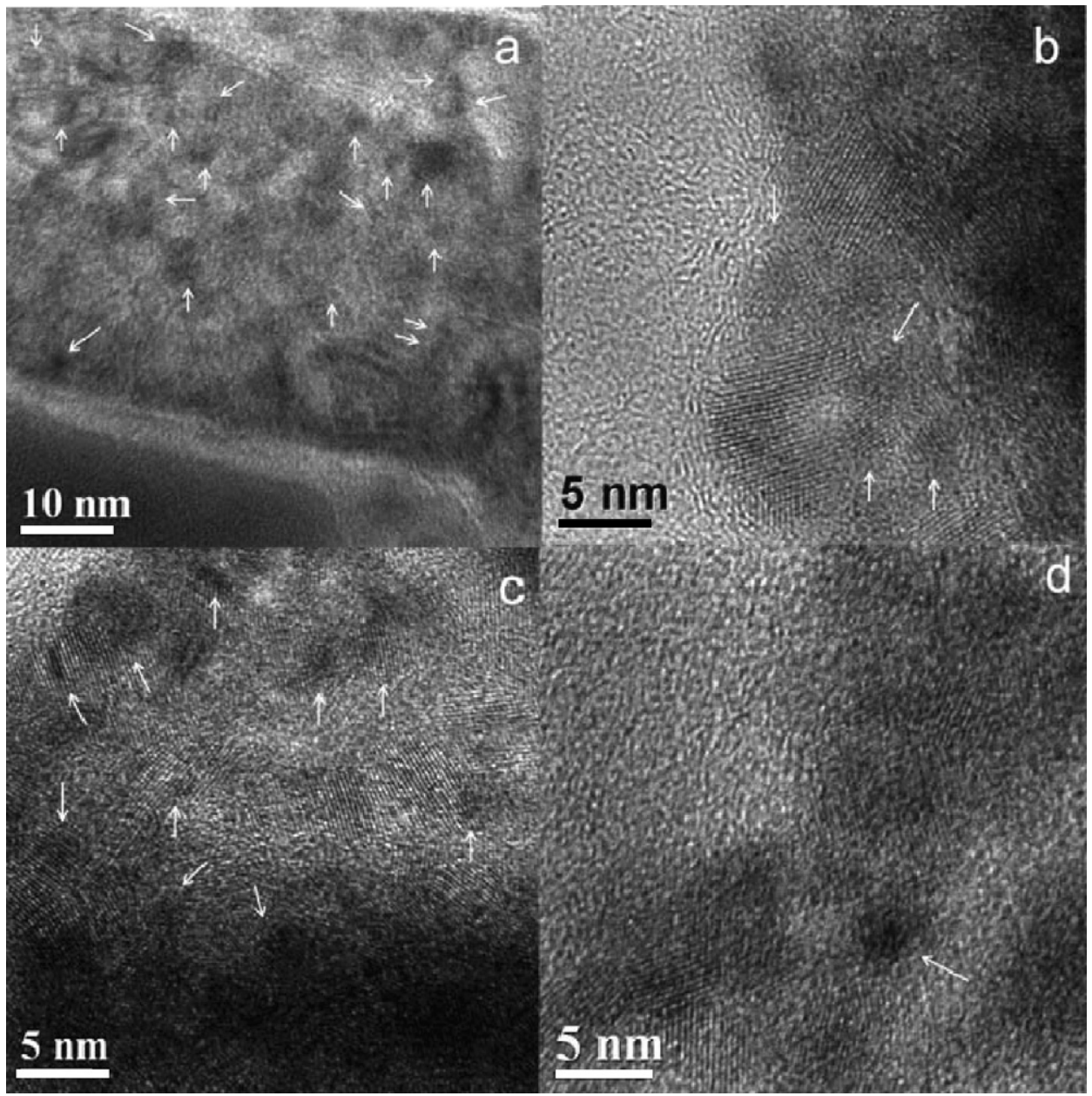

Fig. 6. HRTEM images of the samples: (a) Au/CeSmMA, (b) Au/CeSmCP, (c) Au/CeLaMA, and (d) Au/CeLaCP.

the more defective structure of ceria. The lower RS shifts of the CP samples as compared to the RS widths of the MA catalysts are in opposite to our results reported for the ceria-alumina samples, where the width of the ceria line for $\mathrm{CP}$ catalyst was higher than that for the corresponding MA catalysts.

\subsubsection{TPR profile analysis}

The low temperature (LT) TPR profiles of the gold CP catalysts after direct reduction and after re-oxidation are shown in Fig. 10(a) and (b), respectively. The registered LT TPR peaks are due to the reduction of surface layers of ceria and oxygen species around small gold particles [1,3]. A symmetric TPR peak with $T_{\max }=103{ }^{\circ} \mathrm{C}$ was recorded for the fresh AuCeYCP sample. The AuCeGdCP and AuCeLaCP TPR peaks exhibit identical slightly asymmetric shape with $T_{\max }=108{ }^{\circ} \mathrm{C}$. Finally the lowest $T_{\max }=94{ }^{\circ} \mathrm{C}$ was observed in the complex TPR spectrum for the AuCeSmCP sample. After reoxidation all TPR peaks become broader and less intensive and they are shifted towards the lower temperatures to the corresponding TPR peaks of the fresh samples.

In Fig. 11 the TPR profiles of the gold MA catalysts are compared to the corresponding TPR spectra taken after re-oxidation at $220^{\circ} \mathrm{C}$ (see (a) and (b) in Fig. 11, respectively). In this case again only LT region is shown by the reasons described above. A symmetric and narrow TPR peak with $T_{\max }=125^{\circ} \mathrm{C}$ was recorded for the AuCeYbMA sample, while the samples containing other lanthanides are characterized by complex TPR spectra. For AuCeGdMA sample a peak with $T_{\max }$ at $118{ }^{\circ} \mathrm{C}$ and a shoulder at $149{ }^{\circ} \mathrm{C}$ are registered, whereas two overlapping peaks with $T_{\max }=117 / 155^{\circ} \mathrm{C}$ and $T_{\max }=109 / 140{ }^{\circ} \mathrm{C}$ are observed for the AuCeSmMA and AuCeLaMA samples, respectively. The TPR spectra taken after reoxidation for all samples become broader and similar in shape. The lowest $T_{\max }=78{ }^{\circ} \mathrm{C}$ was observed for the AuCeYbMA catalyst, which exhibited the highest WGS activity.

In order to compare quantitatively the TPR peaks' intensities as indicative for oxygen capacity of the catalysts, we calculated hydrogen consumption (HC). The results are given in Table 3. In the same table the data of gold supported on non-doped ceria (AuCe) are also presented. As it can be seen, the values of HC for the MA catalysts are higher than the values calculated for $\mathrm{CP}$ samples. This relationship is contrary to our observations made on the gold

Table 3

Hydrogen consumption corresponding to the first TPR peak in the spectrum of fresh catalysts and after re-oxidation at $220^{\circ} \mathrm{C}$.

\begin{tabular}{lll}
\hline Samples & $\begin{array}{l}\text { Hydrogen consumption } \\
\text { in direct TPR } \\
\text { spectra }(\mu \mathrm{mol})\end{array}$ & $\begin{array}{l}\text { Hydrogen consumption } \\
\text { after re-oxidation at } \\
200{ }^{\circ} \mathrm{C}(\mu \mathrm{mol})\end{array}$ \\
\hline AuCe & 23.1 & 15.2 \\
AuCeLaCP & 29.9 & 18.3 \\
AuCeSmCP & 29.5 & 18.9 \\
AuCeGdCP & 29.5 & 18.9 \\
AuCeYCP & 34.5 & 13.6 \\
AuCeLaMA & 31.0 & 25.1 \\
AuCeSmMA & 35.9 & 27.9 \\
AuCeGdMA & 29.3 & 24.6 \\
AuCeYbMA & 29.9 & 24.4 \\
\hline
\end{tabular}

The data estimated in Ref. [3]. 

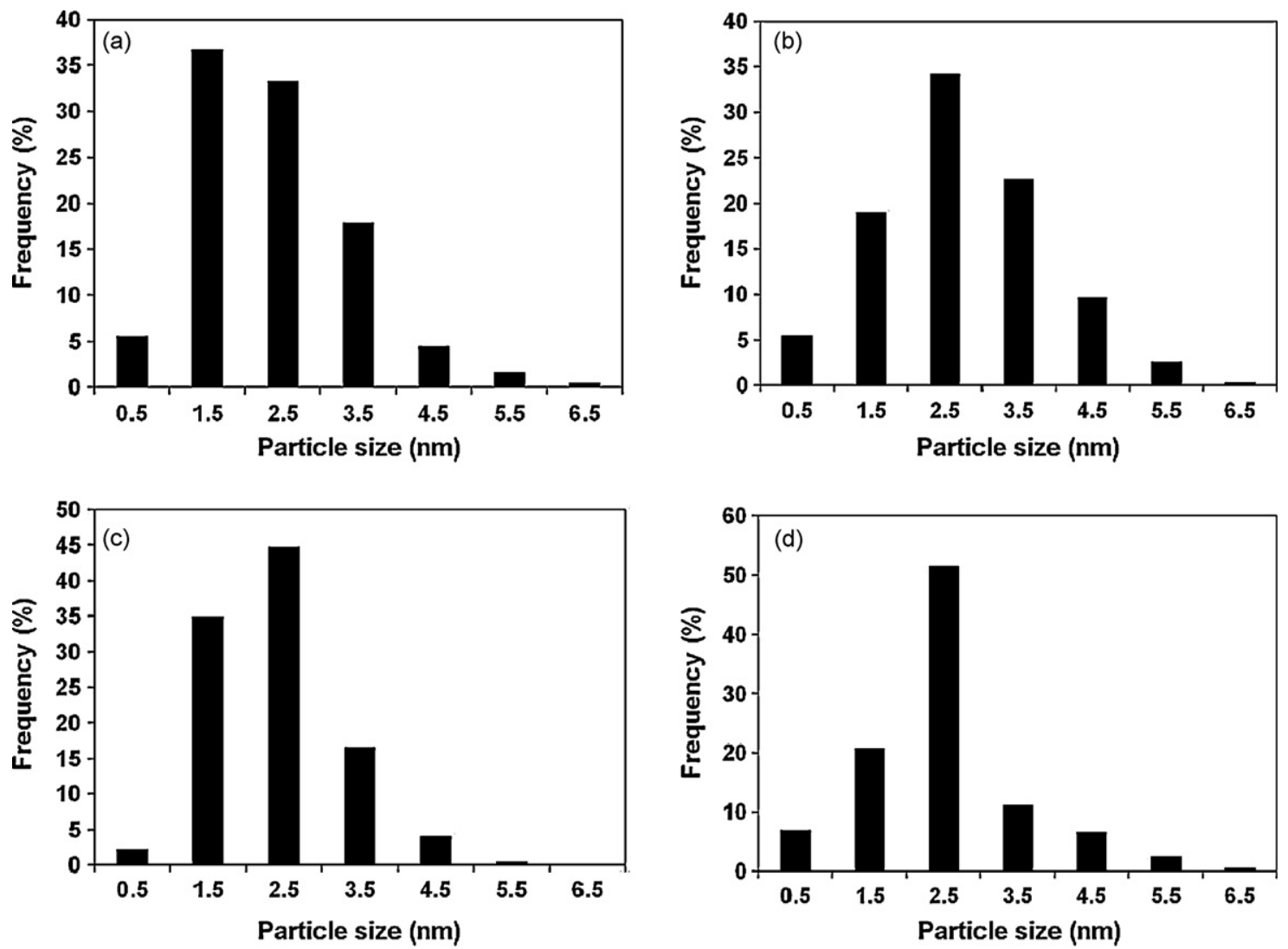

Fig. 7. Size distribution of the gold particles in the samples: (a) Au/CeSmMA, (b) Au/CeSmCP, (c) Au/CeLaMA, and (d) Au/CeLaCP.


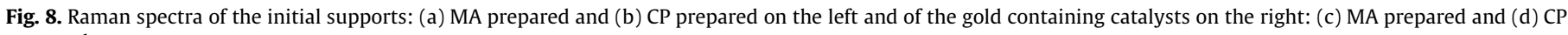
prepared. 

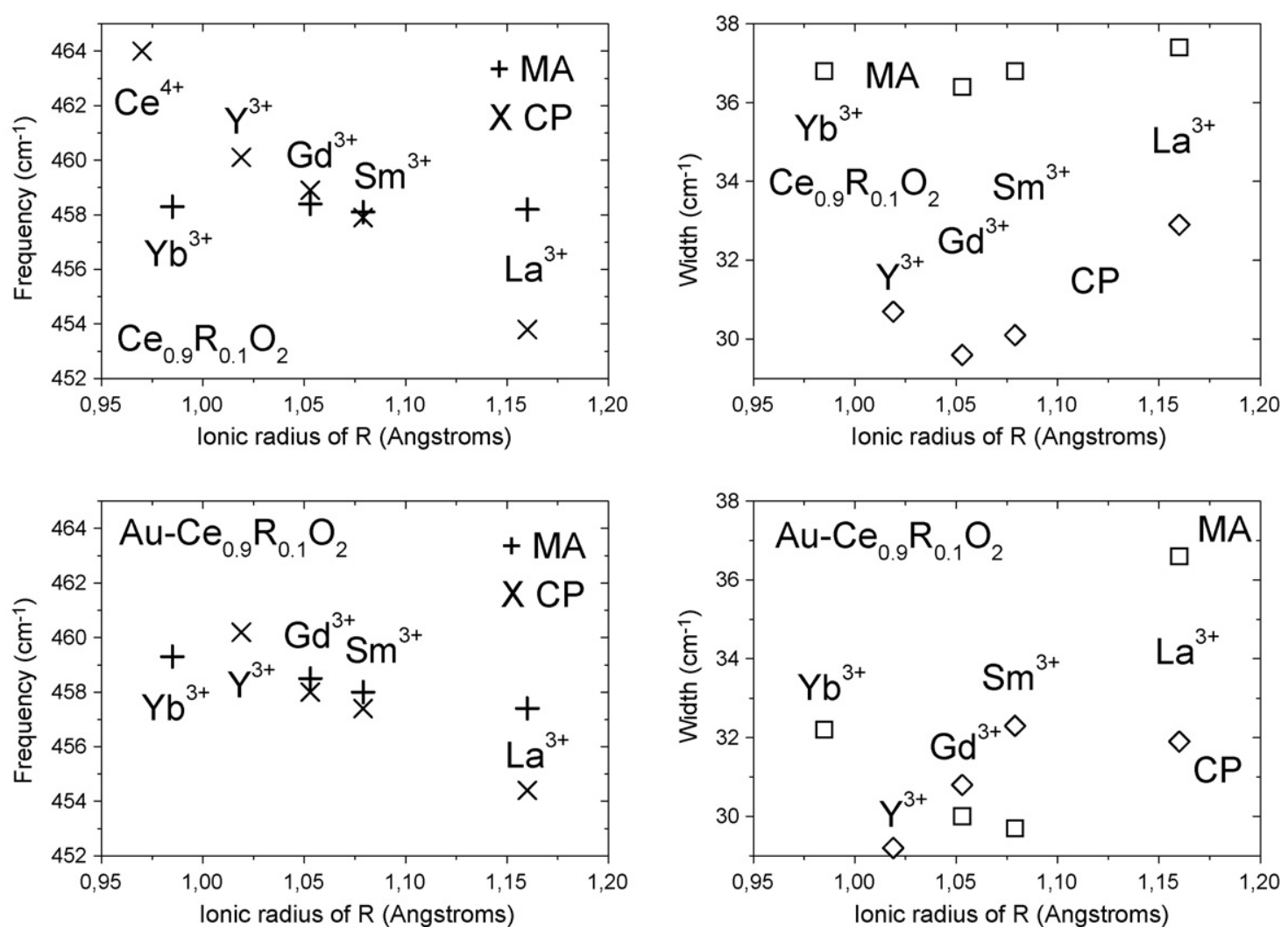

Fig. 9. Dependence of the frequency and width of the main ceria line on the ionic radius in the Raman spectra of the initial supports and gold containing catalysts.

catalysts based on ceria-alumina supports [2,3], but agrees well with the RS data presented above. HC values calculated for Au catalysts doped by lanthanides are higher than that of AuCe. Only in the case of AuCeYCP sample the relatively lower HC value is observed, probably due to the nature of the dopant. After reoxidation the oxygen capacity was not fully recovered and remained lower in the case of $\mathrm{CP}$ samples. For the MA samples this lowering is negligible. It could be said that the oxygen capacity recovers what is in agreement with catalytic activity data.

\subsubsection{XPS analysis}

The catalysts were comparatively characterized by means of XPS as well. The Au 4f XPS spectra for CP and MA samples both fresh and spent, respectively, containing Sm as dopants are shown
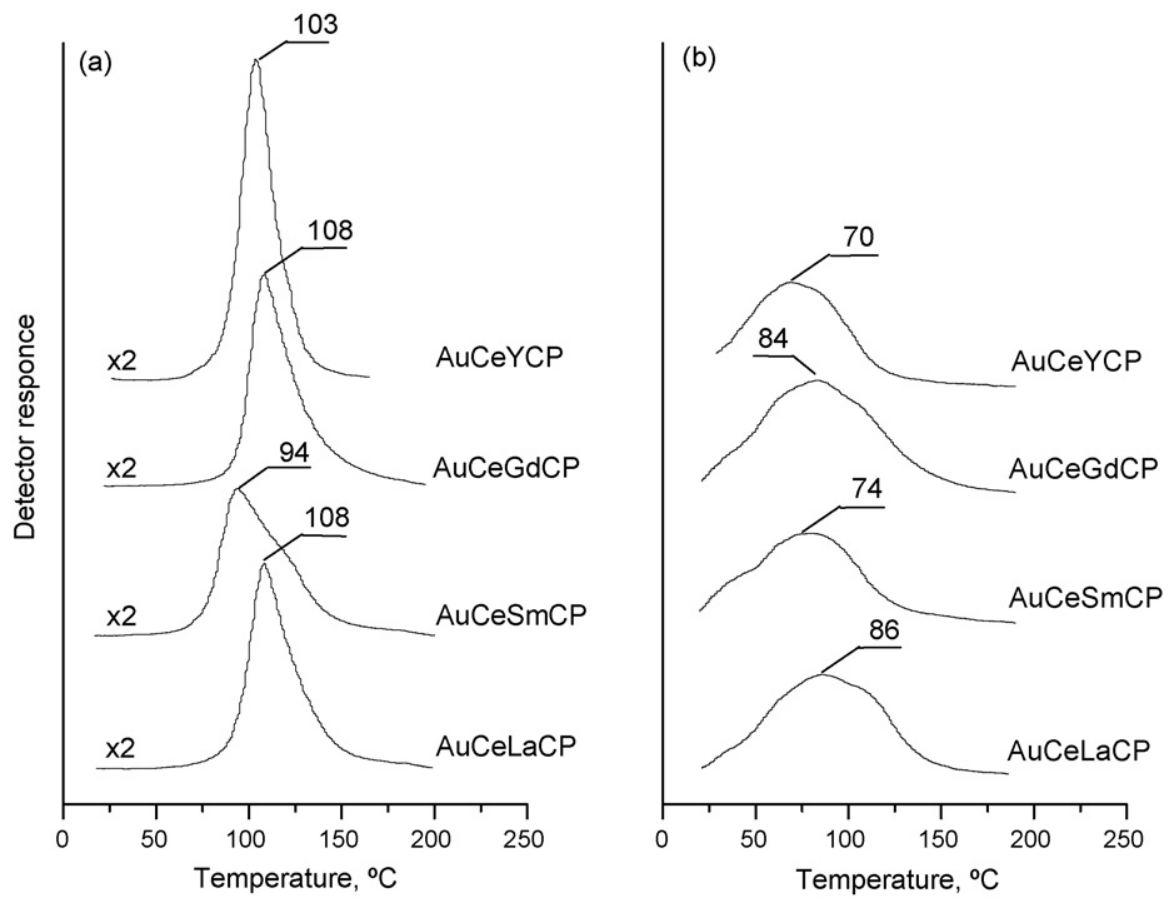

Fig. 10. TPR of the studied CP catalysts: (a) TPR of the fresh samples and (b) TPR after re-oxidation at $200{ }^{\circ} \mathrm{C}$. 



Fig. 11. TPR of the studied MA catalysts: (a) TPR of the fresh samples and (b) TPR after re-oxidation at $200{ }^{\circ} \mathrm{C}$.

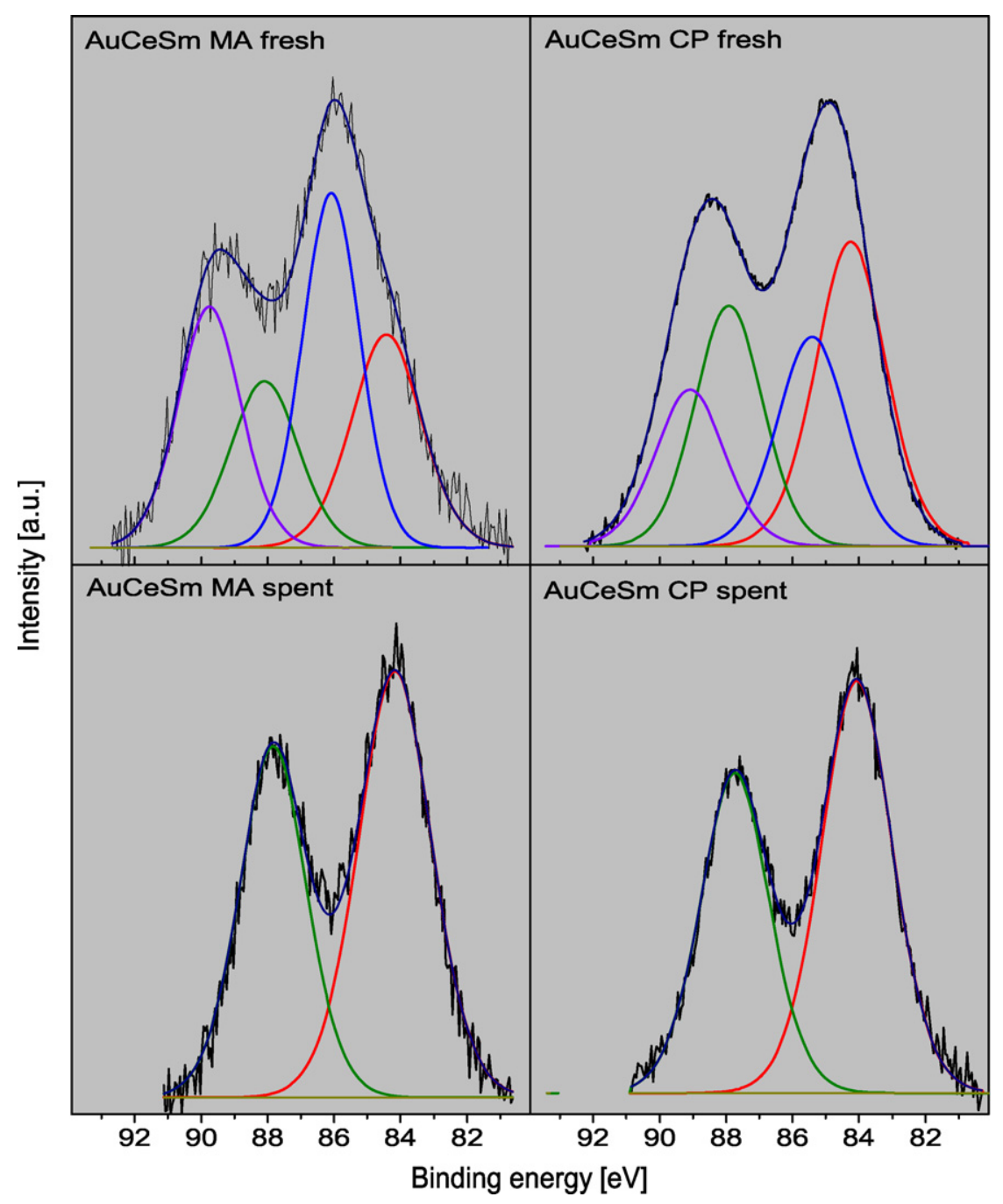

Fig. 12. Experimental and fitted Au 4f XPS spectra of Sm containing CP and MA samples: fresh and spent. 


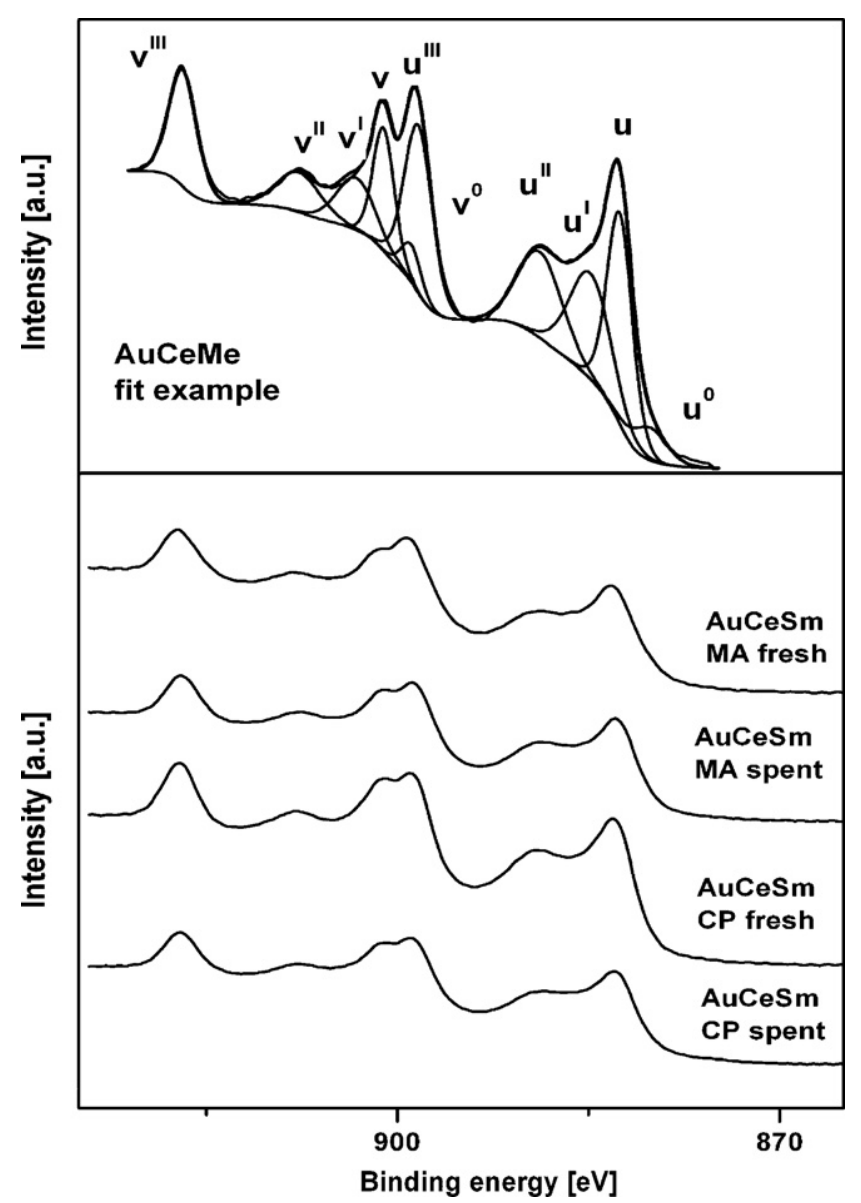

Fig. 13. Experimental and fitted Ce $3 d$ XPS spectra of Sm containing CP and MA samples: fresh and spent.

in Fig. 12. The Ce 3d XPS spectra for the corresponding samples are illustrated in Fig. 13. The XPS data of all studied samples are summarized in Table 4. The Au 4f XPS spectra of the fresh samples were fitted successfully with two or three components; first one at a binding energy ( $\mathrm{BE}$ ) of the $\mathrm{Au} 4 \mathrm{f}_{7 / 2}$ close to the metallic gold $(84 \pm 0.2 \mathrm{eV}$ ) and the second (or third) one at the BE shifted to higher values $(86-87 \mathrm{eV})$. However, after catalytic processing (spent samples) only metallic gold was registered. The component with higher BE we assigned to the positive gold. Careful analysis of the $\mathrm{Ce}$ 3d XPS spectra allows distinguish and quantify the relative contribution of the $\mathrm{Ce}^{3+}$ and $\mathrm{Ce}^{4+}$ compounds. The at.\% of $\mathrm{Ce}^{3+}$ is an useful indicator of the ceria modification by the loading of gold. The rough analysis indicates these values for fresh samples to be relatively high (see Table 4). After catalytic operation the at.\% of $\mathrm{Ce}^{3+}$ generally decreases, but kept a high value for the AuCeSmCP sample.

\section{Discussion}

As it was shown in our previous studies on WGS activity over gold catalysts, supported on ceria-alumina, the catalytic activity strongly depends on the preparation methods of the support used [2,3]. In the case of CP method applied, we observed formation of oxygen vacancies predominantly within the bulk of ceria, while when the MA method was used for preparation the surface modification of ceria-alumina support was found as dominating effect. During the catalytic processing the oxidative capacity of water vapour was too low to oxidize the deeper oxygen vacancies within the bulk of CP samples, resulting in the WGS activity decreasing. When the MA method was used, the WGS activity
Table 4

XPS data of the studied samples.

\begin{tabular}{|c|c|c|c|c|}
\hline \multirow[t]{2}{*}{ Samples } & \multicolumn{2}{|l|}{$\mathrm{Au} 4 \mathrm{f}_{7 / 2}$} & \multicolumn{2}{|l|}{ Ce $3 d_{5 / 2}\left(\mathrm{Ce}^{3+}\right)$} \\
\hline & Peak position & $\mathrm{BE}$ (\% area) & Peak position & BE (at.\%) \\
\hline \multirow[t]{2}{*}{ AuCeLaCP fresh } & 86.00 & 9.81 & 885.43 & 2.93 \\
\hline & 84.89 & 90.19 & 880.30 & 0.65 \\
\hline \multirow{2}{*}{ AuCeSmCP fresh } & 85.61 & 40.14 & 885.71 & 4.93 \\
\hline & 84.45 & 59.86 & 880.40 & 1.28 \\
\hline \multirow[t]{2}{*}{ AuCeSmCP spent } & 84.07 & 100.00 & 886.39 & 4.06 \\
\hline & & & 879.49 & 0.96 \\
\hline \multirow[t]{2}{*}{ AuCeGdCP fresh } & 87.11 & 10,16 & 885.28 & 4.53 \\
\hline & 84.96 & 89.84 & 880.43 & 0.81 \\
\hline \multirow{3}{*}{ AuCeLaMA fresh } & 86.35 & 20.15 & 884.91 & 3.25 \\
\hline & 85.28 & 59.70 & 881.11 & 0.79 \\
\hline & 84.13 & 20.15 & & \\
\hline \multirow[t]{2}{*}{ AuCeSmMA fresh } & 85.91 & 57.31 & 885.85 & 2.70 \\
\hline & 84.25 & 42.69 & 880.08 & 0.73 \\
\hline \multirow[t]{2}{*}{ AuCeSmMA spent } & 84.17 & 100.00 & 885.96 & 2.84 \\
\hline & & & 880.04 & 0.54 \\
\hline \multirow[t]{2}{*}{ AuCeGdMA fresh } & 87.23 & 19.47 & 884.94 & 2.01 \\
\hline & 85.29 & 80.53 & 880.84 & 0.46 \\
\hline \multirow[t]{2}{*}{ AuCeYbMA fresh } & 86.95 & 25.36 & 885.03 & 3.87 \\
\hline & 85.14 & 74.64 & 880.35 & 0.98 \\
\hline \multirow[t]{2}{*}{ AuCeYbMA spent } & 84.16 & 100.00 & 885.77 & 2.40 \\
\hline & & & 879.75 & 0.58 \\
\hline
\end{tabular}

increases with the addition of alumina, becoming higher than the activity of gold/ceria catalysts [2,3]. The other advantage of the loading of alumina as a dopant to ceria was the increase of the stability of the gold and ceria particles against agglomeration, the main reason for the deactivation of gold catalysts during the catalytic operation. In this way the main role of alumina is as a structural promoter increasing the stability of the gold based catalysts, moreover applying MA technique we increase also WGS activity.

In the present study, the influence of the rare earth (RE) dopants' introduced in ceria by different methods was the object of our interests. The energy-minimization calculations of $\mathrm{CeO}_{2}$ reduction indicate that $\mathrm{Ce}^{3+}$ ions should form most easily at the surface because this minimize the penalty associated with the lower Coulombic attraction of $(3+)$ ions with lattice oxygen anions [26]. Zhao and Gorte [27] studying n-butane oxidation have suggested that the presence of dopants could affect the reactivity of the remaining ceria perhaps by decreasing the reducibility of the remaining $\mathrm{Ce}^{4+}$ or decreasing the ability of $\mathrm{Ce}$ cations to stabilize alkyl fragments that must be a part of the reaction mechanism. In addition it should be noted, that the way of the addition of the dopant and the amount of $\mathrm{Me}(3+)$ ions also play a decisive role on the activity based on ceria gold catalysts. In the present study the influence of the dopant nature and the way of its introduction to ceria on the structure and properties as well as on the WGS activity was studied. One of the main reasons should be the differences between the bulk and surface composition of the studied catalysts. When we apply the co-precipitation technique, the XRD showed a single-phase composition, i.e. in this case the dopant replaces the Ce cations in the ceria lattice. From RS data for the dependence of frequency of the dopant's ionic radii (Fig. 9), it is shown that this dependence is linear. In the case of MA method of preparation, the XRD data showed that the all studied samples are double phases and there is no such correlation depending on ionic radii. Another interesting fact is that the width in Raman spectra of the CP sample generally is lower than that of MA ones. This result is opposite to our previous results, obtained for the ceria doped 
by alumina catalysts [2,3]. We suppose that the vacancies are localized around $\mathrm{Me}^{3+}$ dopant and the ceria structure seems to be better ordered than in the case of alumina dopant. In our opinion, this could explain relatively small differences in the catalytic activity between MA and CP samples, because in this case the reoxidation of ceria surface should proceed easier than on the corresponding CP ceria-alumina catalysts [2,3]. Indeed we observe significant increase of WGS activity of all CP catalysts after a long time of catalytic operation and reactivation in air. However this activity is still slightly lower than the WGS activity of the catalytically processed MA samples (see Fig. 4). Only in the case of Sm doped ceria, the AuCeSmCP sample exhibit activity comparable with the AuCeSmMA catalyst. Here, it should be noted that practically there is no differences in the gold particles size (2$3 \mathrm{~nm}$ ) by the data of HRTEM. Seeing the particles size distribution it could be said that gold crystallites in MA samples are slightly smaller in size than that in the CP samples. Obviously, the nature of dopants and the way of introducing in ceria play the more substantial role. According to Zhao et al. $[27,28]$, who studied the RE doped ceria as catalysts for n-butane oxidation, Sm causes the largest increase in ionic conductivity and biggest decrease in activity for n-butane oxidation among all applied RE dopants. The authors supposed that it is energetically more favourable to have $3+$ ions migrate to the surface of cubic fluorite structure [29]. It is possible that the surface could be reached with $\mathrm{Sm}^{3+}$. In our catalysts doped by $\mathrm{Sm}$ the surface amount of $\mathrm{Ce}^{3+}$ is higher compared to all other studied samples, estimated by XPS (see Table 4). Therefore, most probably the higher activity of the doped catalysts should be related to the highest ionic conductivity of ceria in the presence of Sm.

The analysis of TPR results indicates that there is no strong relationship between the reducibility of the samples and their catalytic activities. The oxygen capacity of all studied samples was found to be higher than the nonpromoted gold/ceria catalyst. After re-oxidation at $200{ }^{\circ} \mathrm{C}$, at the temperature closed to the catalytic reaction temperatures, the hydrogen consumption for the MA samples was higher than the $\mathrm{CP}$ catalysts. This conclusion agrees well with Raman spectroscopy data. For the most active $\mathrm{Yb}$ doped sample after re-oxidation, the $T_{\max }$ in TPR peak is lower, which is in accordance with the highest activity of this sample. However, as Zhao and Gorte [26] have commented, the TPR results may not be relevant for the reaction other than hydrogen oxidation and the oxidation state of the catalysts may be very different in TPR and steady-state-reaction conditions.

XPS spectra analysis revealed in the fresh catalysts an additional XPS state at higher BE, which we assigned to positively charged gold species. The contribution of such species seems to be relatively higher than in the case of ceria-alumina gold catalysts [3]. This fact should be related to the higher part of gold with extremely small size, which is in accordance to the HRTEM data. After catalytic operation only metallic gold was registered as in the case of the gold/ceria samples nonpromoted and promoted by alumina, which we have studied previously [2,3]. It should be noted that the surface concentration of $\mathrm{Ce}^{3+}$ for the $\mathrm{Yb}$ and $\mathrm{Sm}$ (CP and MA) doped samples is higher than that of the other studied catalysts. Obviously this could be correlated well with the higher activity of these samples. For the spent $\mathrm{Yb}$ and $\mathrm{Sm}$ doped MA samples, the $\mathrm{Ce}^{3+}$ concentration is high and in the same order. Especially interesting seems to be the AuCeSmCP sample, in which the $\mathrm{Ce}^{3+}$ concentration remains high even after long time catalytic operation. This sample exhibit high WGS activity, even higher than the MA samples doped by Gd and La. This is in accordance with the model, proposed by us, of the active sites and the mechanism of WGS reaction over gold/ceria catalysts, where $\mathrm{Ce}^{3+}$ plays a crucial role [3]. It could be concluded that among the dopants applied, the most appropriated are $\mathrm{Yb}$ and $\mathrm{Sm}$.

\section{Conclusions}

Gold catalysts supported on ceria doped by RE metals were synthesized. Higher WGS activity was found for the catalysts based on doped by $\mathrm{Yb}$ and Sm ceria in comparison to the other doped gold/ceria catalysts. Generally the catalysts prepared by mechanochemical activation exhibit higher activity than those prepared by co-precipitation, but the differences between WGS activities are much smaller than that in the case of ceria-alumina catalysts, studied previously by us $[2,3]$. After reactivating of the catalysts in air, the MA samples almost kept the WGS activity, while the CP catalysts increase it. The catalysts prepared using CP method showed single phase structure, while the catalysts prepared by MA-exhibit double phases. There are no big differences in the gold particle size $(2-3 \mathrm{~nm})$ for the samples prepared by the two methods. The Raman spectroscopy data suggested a larger number of oxygen vacancies for the MA samples than for the corresponding $\mathrm{CP}$ ones. Most probably the oxygen vacancies are adjusted around dopant and the ceria structure seems to be better ordered than in the case of alumina doped ceria. The hydrogen consumption, registered by TPR measurements, both of fresh and re-oxidized samples showed higher oxygen capacity as compared to the nondoped ceria. There is no distinct correlation between reducibility and WGS activity. The surface concentration of partially positively charged gold particles in fresh samples, registered by XPS is high, but after catalytic operation only metallic gold is observable. The surface concentration of $\mathrm{Ce}^{3+}$ in the highly active samples containing $\mathrm{Yb}$ and $\mathrm{Sm}$ is higher than that of the doped by other RE metals. This is in agreement with the model of active sites of gold/ceria catalysts for WGS reaction [3].

\section{Acknowledgements}

This work was supported by the National Science Fund at the Ministry of Education and Science of Bulgaria, project TK-X-1709. M.V.A is gratefully acknowledged for project D01-835. R.Z. acknowledges PUNTA, PAPITT IN106507 and CONACYT 55154 projects.

\section{References}

[1] D. Andreeva, V. Idakiev, T. Tabakova, L. Ilieva, P. Falaras, A. Bourlinos, A. Travlos, Catal. Today 72 (2002) 51-57.

[2] (a) D. Andreeva, I. Ivanov, L. Ilieva, M.A. Abrashev, Appl. Catal. A: Gen. 333 (2007) 153 ;

(b) D. Andreeva, I. Ivanov, L. Ilieva, M.A. Abrashev, Appl. Catal. A: Gen. 302 (2006) 127.

[3] D. Andreeva, I. Ivanov, L. Ilieva, J.W. Sobczak, G. Avdeev, K. Petrov, Top. Catal. 44 (2007) 173-182

[4] F. Qu, S. Kudriavtseva, H. Saltburg, M. Flytzani-Stephanopoulos, Chem. Eng. J. 93 (2003) 41.

[5] T. Bunluesin, R.J. Gorte, Appl. Catal. B: Environ. 15 (1998) 107

[6] T. Shido, Y. Iwasawa, J. Catal. 141 (1993) 71.

[7] J.Z. Shyu, K. Otto, W.L.H. Watkins, G.W. Graham, R.K. Belitz, H.S. Gandhi, J. Catal. 23 (1988) 114.

[8] A. Trovarelli, Catal. Rev. -Sci. Eng. 38 (1996) 439.

[9] Y. Zhang, S. Anderson, M. Muhammed, Appl. Catal. B: Environ. 6 (1995) 325

[10] A.E.C. Palmqvist, E.M. Johansson, S.G. Jaras, M. Muhammed, Catal. Lett. 56 (1998) 69.

[11] A. Luengnaruemitchai, S. Osuwan, E. Gulari, Catal. Commun. 4 (2003) 215.

[12] P. Panagiotopoulou, D. Kondarides, J. Catal. 225 (2004) 327.

[13] P. Panagiotopoulou, A. Christodoulakis, D.I. Kondarides, S. Boghosian, J. Catal. 240 (2006) 114.

[14] P. Panagiotopoulou, D. Kondarides, Catal. Today 112 (2006) 49.

[15] P. Panagiotopoulou, J. Papavasiliou, G. Avgouropoulos, T. Ioannides, D.I. Kondarides, Chem. Eng. J. 134 (2007) 16.

[16] W. Kraus, G. Nolze, PowderCell for Windows, Version 2.4, Federal Institute for Materials Research and Testing, Rudower Chaussee, 12489 Berlin, Germany.

[17] N. Kotzev, D. Shopov, J. Catal. 22 (1971) 297.

[18] D.A.M. Monti, A. Baiker, J. Catal. 83 (1983) 323

[19] M. Romeo, K. Bak, J. El Fallah, F. Le Normand, Surf. Interface Anal. 20 (1993) 508.

[20] L. Armelao, D. Barecca, G. Bottaro, A. Gasparotto, E. Tondello, Surf. Sci. Spectra 8 (2001) 247. 
[21] A.Q. Wang, P. Punchaipetch, R.M. Wallace, T.D. Golden, J. Vac. Sci. Technol. B 21 (2003) 1169.

[22] T. Tabakova, F. Boccuzzi, M. Manzoli, D. Andreeva, Appl. Catal. A: Gen. 252 (2003) 385.

[23] J.R. McBride, K.C. Hass, B.D. Poindexter, W.H. Weber, J. Appl. Phys. 76 (1994) 2435.

[24] G.W. Graham, W.H. Weber, C.R. Peters, R. Usmen, J. Catal. 130 (1991) 310.
[25] I. Kosacki, T. Suzuki, H.U. Anderson, Ph. Colomban, Solid State Ionics 149 (2002) 99.

[26] S. Zhao, R.J. Gorte, Appl. Catal. A 248 (2003) 9.

[27] S. Zhao, R.J. Gorte, Appl. Catal. A 277 (2004) 129.

[28] H. Cordatos, D. Ford, R.J. Gorte, J. Phys. Chem. 100 (1996) 182128.

[29] H. Cordatos, T. Bunluesin, J. Stubenrauch, J.M. Vohs, R.J. Gorte, J. Phys. Chem. 100 (1996) 785. 